\title{
The Immunosuppressive Effect of Gamisanghyulyunbueum through Inhibition of Mitogen-Activated Protein Kinase and Nuclear Factor Activation in MOLT-4 Cells
}

\author{
Hye-Young Shin, ${ }^{a, b}$ Hyun-Ja Jeong, ${ }^{a}$ Ho-Jeong NA,${ }^{a}$ Hong-Joon KIM,${ }^{c}$ Goo Moon, ${ }^{c}$ Tae-Yong ShIN, ${ }^{d}$ \\ Deok-Chun YANG, ${ }^{e}$ Seung-Heon HoNG, ${ }^{b}$ and Hyung-Min $\mathrm{KIM}^{*, a}$ \\ ${ }^{a}$ College of Oriental Medicine, Kyung Hee University; 1 Hoegi-Dong, Dongdaemun-Gu, Seoul, 130-701, South Korea: \\ ${ }^{b}$ College of Pharmacy, Wonkwang University; ${ }^{c}$ College of Oriental Medicine, Wonkwang University; Iksan, Jeonbuk \\ 570-749, South Korea: ' College of Pharmacy, Woosuk University; Jeonju, Jeonbuk, 565-701, South Korea: and \\ ${ }^{e}$ Department of Oriental Medicine Material and Processing, Kyung Hee University; Suwon, 449-701, South Korea. \\ Received December 10, 2004; accepted March 25, 2005
}

Gamisanghyulyunbueum (GSHYBE) has been used clinically to treat skin related disease in South Korea. We investigated GSHYBE-mediated changes in downstream $T$ cell signal transduction. To determine the mechanism of inhibition, we have studied many of the major pathways in phytohemagglutinin (PHA)-activated $\mathrm{T}$ cell. We show that among the mitogen-activated protein kinase family activation of phosphorylation of extra cellular signal-regulated kinase $1 / 2\left(\right.$ ERK1/2, p44/42) and p38, but not c-jun $\mathrm{NH}_{2}$-terminal kinase is inhibited. In activated MOLT-4 cells, the nuclear localization of nuclear factor of activated $T$ cells (NFATc) was blocked by GSHYBE $(1 \mathrm{mg} / \mathrm{ml})$. Also, degradation of inhibitor $\kappa \mathrm{B}-\alpha$ and transactivation by nuclear factor- $\kappa \mathrm{B}(\mathrm{NF}-\kappa \mathrm{B}) / \mathrm{Rel}$ $A$ were impaired by GSHYBE $(1 \mathrm{mg} / \mathrm{ml})$. Furthermore, interlukin (IL)-2, IL-4 and Interferen (IFN)- $\gamma$ secretion by PHA activated MOLT-4 cells and peripheral blood mononuclear cells (PBMC) were significantly diminishes following GSHYBE treatment $(1 \mathrm{mg} / \mathrm{ml})$. Also, oral administration of GSHYBE inhibited IL-2 secretion in skin allergic reaction. In conclusion, our data indicate that GSHYBE treatment of $T$ cells inhibits ERK1/2 and p38 activation and nuclear translocation of NFATc, NF- $\kappa \mathrm{B}$, resulting in diminished secretion of IL-2.

Key words Gamisanghyulyunbueum; mitogen-activated protein kinase; NFATc; nuclear factor- $\kappa /$ Rel $A$; interlukin-2

Typical Korean traditional medicines consist of 3 to 15 components that are mixed to minimize side effects and maximize medicinal effects. Traditional medicines appear to exert their pharmacological actions through the synergistic effects of their components and via drug interaction. Therefore, they may modulate biological responses, including immune responses, rather than acting through the direct activity of the individual components. ${ }^{1,2}$

Gamisanghyulyunbueum (GSHYBE) is a traditional Oriental herbal medicine prescription, which has been used for the treatment of allergic disorders such as atopic dermatitis and especially, skin related disease. ${ }^{3)}$ However, its mechanism has not been investigated experimentally.

Activation of $\mathrm{T}$ cells is a very complex process that involves cell-to-cell interactions of several cell surface molecules. Engagement of the T cell antigen receptor (TcR) with the antigen-major histocompatibility complex on antigenpresenting cells triggers a complex TcR signaling cascade that leads to $\mathrm{T}$ cell activation and cytokine secretion. ${ }^{4)} \mathrm{In}$ consequence to early protein phosphorylation steps and calcium response, mitogen-activated protein kinases (MAPKs) are activated by phosporylation. The three major family of MAPKs, c-Jun $\mathrm{NH}_{2}$-terminal kinases (JNK), extracellular signal-regulated kinases (ERK), and p38 MAPK, are regulated by distinct but cross-talking signaling cascades. ${ }^{5)}$ Such signals culminate in the activation of transcription factors such as nuclear factor- $\kappa \mathrm{B}(\mathrm{NF}-\kappa \mathrm{B})$ and the nuclear factor of activated T cells (NFAT). ${ }^{6-8)}$

The transcription factor NFAT plays an essential role in IL-2 expression. Among of NFAT family members, NFAT1, NFAT2 (NFATc1), and NFAT4 are involved in the transcriptional activation of genes encoding cytokines including IL-2 and IL-4, and CD40 ligand. ${ }^{9)}$ NFAT2 is induced following T cell stimulation to the same level as NFAT1; however, in nuclear extracts from activated T cells, nearly all the NFAT that bound to a prove corresponding to the distal NFAT site of the human IL-2 promoter was attributable to NFAT1. ${ }^{10)}$ In contrast to normal T cells, NFAT2 seems to play the major role in driving IL-2 transcription in Jarket T cells. ${ }^{11)} \mathrm{NF}-\kappa \mathrm{B}$ plays a central role in a number of signaling pathways in many cell types. ${ }^{12)}$ Fundamental processes such as cell growth, apotosis, and development are regulated by NF- $\kappa \mathrm{B}$, and NF- $\kappa \mathrm{B}$ is a central mediator of immune, inflammatory, and stress response. ${ }^{13)}$ The predominantly characterized NF- $\kappa \mathrm{B}$ complex is a p50-p65 heterodimer, which at rest is retained in the cytoplasm and is associated with an inhibitor molecular, $\mathrm{I} \kappa \mathrm{B} .^{7)}$ During $\mathrm{T}$ cell activation, $\mathrm{I} \kappa \mathrm{B} \alpha$ is phosphorylated and becomes ubiquitinated, leading to degradation of $\mathrm{I} \kappa \mathrm{B} \alpha$ and translocation of NF- $\kappa \mathrm{B}$ to the nucleus. These transcription factors bind recognition sites within promoter sequences to induce transcription of cytokines, including IL-2 the major T lymphocyte proliferation factor. ${ }^{14)}$ Thus, $\mathrm{T}$ cell stimulation leads to IL production and proliferation, thereby promoting the adaptive immune response.

This study attempts to find scientific understanding of the immunosuppressive effect of GSHYBE on the activated human $\mathrm{T}$ cell line MOLT-4 cells and peripheral blood mononuclear cells (PBMC). We investigated the mechanism of action of activated MOLT- 4 cells by determining which signaling pathways were affected. We investigated whether GSHYBE inhibits $T$ cell activation on the MAPK and nuclear factor level. Also, we investigated the effect of GSHYBE on the secretion of IL-2 in activated MOLT- 4 cells and PBMC. 


\section{MATERIALS AND METHODS}

Preparation of GSHYBE Each herb of GSHYBE was obtained from an oriental drug store, College Oriental Pharmacy (Iksan, Republic of Korea) and authenticated by Professor K. Moon, College of Oriental Medicine, Wonkwang University. A voucher specimen (number 01-37-46) was deposited at the Herbarium of the College of Pharmacy, Wonkwang University. An extract of GSHYBE was prepared by decocting the dried prescription of herbs with boiling distilled water $(57.2 \mathrm{~g} / \mathrm{l})$. The duration of decoction was about $3 \mathrm{~h}$. The decoction was filtered, lyophilized and kept at $4{ }^{\circ} \mathrm{C}$. The yield of extraction was about $14 \%(\mathrm{w} / \mathrm{w})$. The GSHYBE water extract powder was dissolved in sterile saline $(50 \mathrm{mg} / \mathrm{ml})$. The ingredients of $57.2 \mathrm{~g} \mathrm{GSHYBE}$ include $6 \mathrm{~g}$ of Aspargus tuber (Liliaceae), $4 \mathrm{~g}$ of Rehmanniae radix (Scrophulariaceae), steamed Rehmanniae radix (Scrophulariaceae), Ophiopogonis tuber (Liliaceae), Angelicae gigantis radix (Umbelliferae), Astragali radix (Leguminosae), $2 \mathrm{~g}$ of Scutellariae radix (Labiatae), Trichosanthis semen (Cucurbitaceae), Persicae semen (Rosaceae), $0.8 \mathrm{~g}$ of Cimicifugae rhizoma, $0.4 \mathrm{~g}$ of Carthami flos (Compositae), Puerariae radix (Leguminosae), $8 \mathrm{~g}$ of Cortex betulae platyphyllae (Betulaceae), $4 \mathrm{~g}$ of Ponciri fructus (Rutaceae), Fructus ponciri seu aurantii (Rutaceae).

Reagents Cell culture medium, RPMI 1640 was purchased from Gibco BRL (Grand Island, NY, U.S.A.). Phytohemagglutinin (PHA) was purchased from Calbiochem ( $\mathrm{La}$ Jolla, CA, U.S.A.). Avidin-peroxidase, 2,2' -azio-bis(3-ethylbenzthiazoline-6-sulfonic acid), 3-(4,5-dimethylthiazol-2-yl)diphenyltetrazolium bromide (MTT), Ficoll-Hypaque and other reagents were obtained from sigma (St. Louis, MO, U.S.A.). Anti-human (or mouse) IL-2, IL-4 and Interferon (IFN)- $\gamma$ antibody (Ab), biotinylated anti-human (or mouse) IL-2, IL-4 and IFN- $\gamma \mathrm{Ab}$, and recombinant human (or mouse) IL-2, IL-4 and IFN- $\gamma$ were purchased from R\&D Systems (Minneapolis, MN, U.S.A.). NFATc1 and NF- $\kappa$ B (p65) antibodies were purchased from Santa Cruz biotechnology (Santa Cruz, CA, U.S.A.). JNK, ERK, p38 and phosphorylated antibodies were purchased from Santa Cruz Biotechnology (Santacruz, CA, U.S.A.).

Culture of MOLT-4 Cells All experiments were performed on T cell line MOLT-4. MOLT- 4 cells were grown in RPMI 1640 medium supplemented with $10 \%$ fetal bovine serum (FBS), $100 \mathrm{U} / \mathrm{ml}$ penicillin and $100 \mu \mathrm{g} / \mathrm{ml}$ streptomycin at $37^{\circ} \mathrm{C}$ in the presence of $5 \% \mathrm{CO}_{2}$.

Western Blot Analysis Cell extracts were prepared by detergent lysis procedure. Cells $\left(5 \times 10^{6}\right.$ cells $)$ were scraped, washed once with PBS, resuspended in lysis buffer. Samples were vortexed for lysis for a few seconds every $15 \mathrm{~min}$ at $4^{\circ} \mathrm{C}$ for $1 \mathrm{~h}$ and centrifuged at $15000 \times \mathrm{g}$ for $5 \mathrm{~min} 4{ }^{\circ} \mathrm{C}$. Samples were heated at $95^{\circ} \mathrm{C}$ for $5 \mathrm{~min}$, and briefly cooled on ice. Following the centrifugation at $15000 \times \mathbf{g}$ for $5 \mathrm{~min}$, $50 \mu \mathrm{l}$ aliquots were resolved by $12 \%$ SDS-PAGE. Resolved proteins were transferred overnight to nitrocellulose membrane in $25 \mathrm{~mm}$ Tris, $\mathrm{pH} 8.5,0.2 \mathrm{~mm}$ glycerin, $20 \%$ methanol at $25 \mathrm{~V}$. Blots were blocked for at least $2 \mathrm{~h}$ with $1 \times$ TBST containing $10 \%$ nonfat dry milk. Protein levels were analyzed essentially according to the manufacturer's instructions.

Nuclear Protein Extraction Preparation of crude nu- clear extract was basically as described previously. ${ }^{15)}$ Briefly, after cell activation for the times indicated, $1 \times 10^{7}$ cells were washed in $1 \mathrm{ml}$ of ice-cold PBS, centrifuged at $1000 \times \boldsymbol{g}$ for $5 \mathrm{~min}$, resuspended in $400 \mu \mathrm{l}$ of ice-cold hypotonic buffer (10 mм HEPES/KOH, $2 \mathrm{~mm} \mathrm{MgCl}_{2}, 0.1 \mathrm{~mm}$ EDTA, $10 \mathrm{~mm} \mathrm{KCl,}$ $1 \mathrm{~mm}$ DTT, $0.5 \mathrm{~mm}$ PMSF, pH 7.9), left on ice for $10 \mathrm{~min}$, vortexed, and centrifuged at $15000 \times \boldsymbol{g}$ for $30 \mathrm{~s}$. Pelleted nuclei were gently resuspended in $50 \mu \mathrm{l}$ of ice-cold saline buffer $(50 \mathrm{~mm}$ HEPES/KOH, $50 \mathrm{~mm} \mathrm{KCl}, 300 \mathrm{mM} \mathrm{NaCl}$, $0.1 \mathrm{~mm}$ EDTA, 10\% glycerol, $1 \mathrm{~mm}$ DTT, $0.5 \mathrm{~mm}$ PMSF, pH 7.9), left on ice for $20 \mathrm{~min}$, vortexed, and centrifuged at $15000 \times \mathbf{g}$ for $5 \mathrm{~min} 4{ }^{\circ} \mathrm{C}$. Aliquots of the supernatant that contain nuclear proteins were frozen in liquid nitrogen and store at $-70^{\circ} \mathrm{C}$. Protein was determined using a Bicinchoninic acid protein assay method (Sigma, St. Louis, MO, U.S.A.).

Transcription Factor Enzyme-Linked Immunoassay (TF-EIA) Avidin peroxidase coated at 96 well ELISA plate. Coated plate was washed with PBST and then blocked with 3\% skim milk solution. Coated plate was incubated with $1 \mu \mathrm{g} / \mathrm{ml}$ of $5^{\prime}$-biotinylated 21 single strand DNA oligonucleotide sequence for $1 \mathrm{~h}$ at room temperature. This sequence contains the previously described NF- $\kappa \mathrm{B}$ binding motif. The sequences used here were: 5'-AGTTGAGGGGACTTTCCCAGG-3'. DNA binding reaction was carried out in a total volume $100 \mu \mathrm{l}$ containing $10 \mu \mathrm{g}$ nuclear protein extract in a buffer containing $10 \mathrm{~mm}$ HEPES ( $\mathrm{pH} 7.9$ ), $50 \mathrm{~mm} \mathrm{NaCl}$, $5 \%$ glycerol, $1 \mathrm{~mm}$ EDTA, and $1 \mathrm{~mm}$ DTT, for $1 \mathrm{~h}$ at room temperature and then washed. NF- $\kappa \mathrm{B}$ antibodies were then added at a $1: 500$ concentration in PBS containing 3\% BSA for $1 \mathrm{~h}$, followed by the addition of the corresponding alkaline phosphatase (AP)-coupled secondary antibody. Between each addition, wells were extensively washed in PBST. AP activity was then detected by the addition of $p$-nitrophenyl phosphate (PNPP) solution (Sigma). After a 10 min incubation period, the reaction was arrested by the addition of $0.5 \mathrm{M}$ $\mathrm{H}_{2} \mathrm{SO}_{4}$, Color intensity was detected at $405 \mathrm{~nm}$ using ELISA reader. AP activity was normalized to control values (unstimulated cells).

PBMC Isolation and Culture PBMC (5 healthy adults volunteers) from heparinized venous blood were isolated by Ficoll-gradient centrifugation, washed three times in phosphated-buffered saline (PBS) solution and resuspended in RPMI 1640 medium (GIBCO) supplemented with $2 \mathrm{~mm} \mathrm{L-}$ glutamin, $100 \mathrm{U} / \mathrm{ml}$ penicillin $\mathrm{G}, 100 \mu \mathrm{g} / \mathrm{ml}$ streptomycin, and $10 \% \mathrm{FBS}$ inactivated for $30 \mathrm{~min}$ at $56^{\circ} \mathrm{C}$. PBMC were cultured for $24 \mathrm{~h}$ in $95 \%$ humidified air containing $5 \% \mathrm{CO}_{2}$ $\left(37^{\circ} \mathrm{C}\right)$, in the presence or the absence of PHA, and the supernatants were collected by centrifugation and stored at $-20^{\circ} \mathrm{C}$

Passive Cutaneous Anaphylaxis (PCA) An IgE-depedent cutaneous reaction was generated by sensitizing the skin with an i.d. injection of anti-DNP IgE followed $48 \mathrm{~h}$ later with an injection of DNP-HSA into the mice's tail vein. The DNP-HSA was diluted in PBS. The mice were injected intradermally with $100 \mu \mathrm{g}$ of anti-DNP IgE (a mean value) into each of 2 dorsal skin sites that had been shaved $48 \mathrm{~h}$ earlier. The sites were outlined with a water-insoluble red marker. Forty-eight hours as later each rat received an injection of $1 \mathrm{mg}$ of DNP-HSA in PBS containing 4\% Evans blue $(1: 4)$ via the tail vein. GSHYBE was orally administered $1 \mathrm{~h}$ be- 
fore the challenge. Thirty minutes after the challenge, the mice were killed and the dorsal skin was removed. The dorsal skin homogenized in homogenization buffer $(20 \mathrm{~mm}$ HEPES $\mathrm{pH} 7.5,1.5 \mathrm{~mm} \mathrm{MgCl}_{2}, 0.2 \mathrm{~mm}$ EDTA $\mathrm{pH} 8.0$, $0.2 \mathrm{~mm}$ DTT, $0.5 \mathrm{~mm} \mathrm{Na}_{3} \mathrm{VO}_{4}$, protease inhibitor cocktail). For cytokine assay, the supernatants were collected by centrifugation and stored at $-20^{\circ} \mathrm{C}$.

Cytokine Assay IL-2, IL-4 and IFN- $\gamma$ secretion was measured by modification of an enzyme-linked immunosorbent assay (ELISA) as described previously. ${ }^{16)}$ MOLT-4 cells and PBMC were cultured with RPMI 1640 plus 10\% FBS and resuspended in Tyrode buffer A. The cells were sensitized with PHA $(25 \mu \mathrm{g} / \mathrm{ml})$ for $24 \mathrm{~h}$ in the absence or presence of GSHYBE. The ELISA was sensitive IL-2, IL-4 and IFN- $\gamma$ concentrations in the medium above $0.01 \mathrm{ng} / \mathrm{ml}$. The ELISA performed by coating 96-well plates (Nunc, Denmark) with $6.25 \mathrm{ng} /$ well of murine monoclonal $\mathrm{Ab}$ with specificity for IL-2, IL-4 and IFN- $\gamma$. Before use and between subsequent steps in the assay, the coated plates were washed twice with PBS containing $0.05 \%$ Tween-20 and twice with PBS alone. All reagents used in this assay and the coated wells were incubated for $1 \mathrm{~h}$ at room temperature. For the standard curve, IL-2, IL-4 and IFN- $\gamma$ was added to serum previously determined to be negative for endogenous IL-2, IL-4 and IFN- $\gamma$. After exposure to the medium, the assay plates were exposed sequentially to biotinylated anti-human IL-2, IL-4 and IFN- $\gamma, 2,2^{\prime}$-azino-bis(3-ethylbenzthiazoline6-sulfonic acid) tablets substrates. Optical density readings were made within 10 min of the addition of the substrate on a Titertek Multiscan (Flow Laboratories) with a $405 \mathrm{~nm}$ filter.

MTT Assay Cell viability was determined by the MTT assay. Briefly, $500 \mu \mathrm{l}$ of MOLT-4 cells suspension $\left(3 \times 10^{5}\right.$ cells) was cultured in 4-well plates for $24 \mathrm{~h}$ after treatment by each concentration of GSHYBE. Twenty microliters of MTT solution $(5 \mathrm{mg} / \mathrm{ml})$ was added and the cells were incubated at $37^{\circ} \mathrm{C}$ for an additional $4 \mathrm{~h}$. After washing the supernatant out, the insoluble formazan product was dissolved in DMSO. Then, optical density of 96-well culture plates was measured using an ELISA reader at $540 \mathrm{~nm}$. The optical density of formazan formed in untreated control cells was taken as $100 \%$ of viability.

HPLC Analysis The chromatographic system consisted of a pump (Water Assoc., U.S.A.: 600E HPLC pump), a UV detector (Linear: UVIS 200 detector), an autosampler (Water Assoc., U.S.A.: 717 plus autosampler), and a date modular (Water Assoc., U.S.A.: 746 computing integrator). A $\mu$ Bondapak $^{\mathrm{TM}} \mathrm{C} 18$ Waters column $(3.9 \mathrm{~mm} \times 300 \mathrm{~mm})$ was used. Water-acetonitrile-acetic acid $(70: 30: 1)$ was used as the mobile phase. Detection of the peaks was made at $254 \mathrm{~nm}$ and the sensitivity was set of 1.0 AUFS. The injection volume was $20 \mu \mathrm{l}$ and flow rate was $1.0 \mathrm{ml} / \mathrm{min}$. Standard solution was prepared by dissolving in distilled water $(100 \mu \mathrm{g} / \mathrm{ml})$. The solution was filtered through $0.45 \mu \mathrm{m}$ membrane filter and applied to HPLC. Acetonitrile-HPLC grade was purchased from Merck (Germany). Other chemicals were used all GR grade.

Statistical Analysis Each datum represents the mean \pm S.E.M. of the different experiments under the same conditions. The Student's $t$-test was used to make a statistical comparison between the groups. Results with $p<0.05$ were considered statistically significant.

\section{RESULTS}

GSHYBE Selectively Blocks ERK, p38 Activation But Not JNK To study the impact of GSHYBE treatment on downstream $\mathrm{T}$ cell signaling, we first analyzed effects on the level of MAPK activation. Activation of MAPK relies on phosphorylation of specific tyrosine and threonine residues. $^{17)}$ Investigation of the activation of $\mathrm{JNK} 1 / 2$, ERK1/2, and p38 pathways, as determined by assaying their phosphorylation, showed that both ERK1/2 and p38 activation inhibited by GSHYBE, when stimulated for $10 \mathrm{~min}$ with PHA (Figs. 1B, C). However, phosphorylation of JNK1/2 induced PHA, was not altered by GSHYBE treatment (Fig. 1A). Hence, GSHYBE treatment of MOLT-4 cells inhibits ERK1/2 and p38 activation but does not interfere with phosphorylation of other MAPKs, JNK1/2.

GSHYBE Inhibits the Nuclear Localization of NFATc1 and NF- $\boldsymbol{K B} / \boldsymbol{R e l} \boldsymbol{A}$ Production of the central T cell growth factor IL-2 critically depends on activation of the transcription factors NFAT, NF- $\kappa$ B. ${ }^{14)}$ The effect of GSHYBE on nuclear translocation of NFATc 1 and NF- $\kappa \mathrm{B} /$ Rel $A$ in activated MOLT-4 cells was examined by western blot analysis. In PHA-stimulated cells, the expression level of NFATc1 increased in the nucleus. However, the expression level of NFATc1 in nucleus decreased by treatment of GSHYBE (Fig. $2 \mathrm{~A})$. As a marker of NF- $\kappa \mathrm{B}$ activation, we detected the degradation of $\mathrm{I} \kappa \mathrm{B}-\alpha$ in cell lysates. Activation and nuclear translocation of NF- $\kappa \mathrm{B}$ is dependent on the phosphorylation of $\mathrm{I} \kappa \mathrm{B}-\alpha$, which is then rapidly degraded. In PHA-stimulated cells, the expression level of $\mathrm{I} \kappa \mathrm{B}-\alpha$ decreased in the cytoplasm and the level of NF- $\kappa \mathrm{B} / \operatorname{Rel} A$ increased in the nucleus. But, the expression level of NF- $\kappa \mathrm{B} / \operatorname{Rel} A$ decreased by treatment of GSHYBE (Fig. 2B). We also investigated the effect of GSHYBE on PHA-induced NF- $\kappa \mathrm{B}$ transcription complex. To perform these studies, we used an NF- $\kappa$ B TF-EIA method. This assay has the advantage of being 10 times more sensitive than electrophoretic mobility shift assay and allows greater flexibility in the experimental step. As shown in Fig. $2 \mathrm{D}$, PHA increased DNA-binding activity for NF- $\kappa \mathrm{B}$. But in-

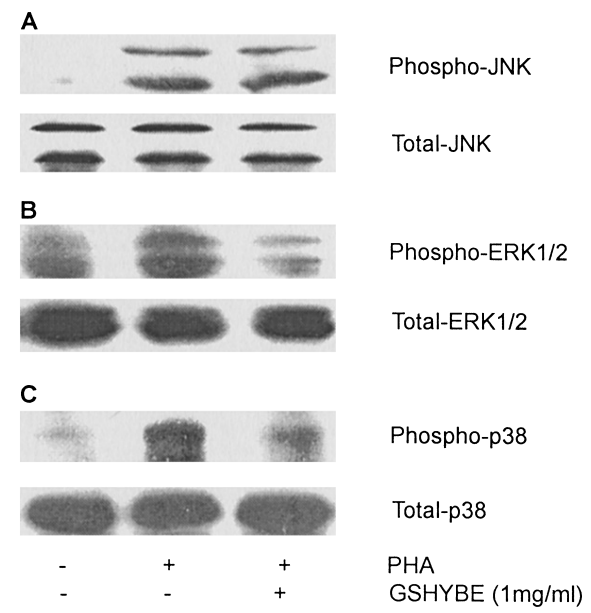

Fig. 1. Effect of GSHYBE on MAPK Activation

MOLT- 4 cells $\left(5 \times 10^{6}\right)$ were treated with GSHYBE $(1 \mathrm{mg} / \mathrm{ml})$ for $30 \mathrm{~min}$ and then stimulated with PHA $(25 \mu \mathrm{g} / \mathrm{ml})$ for $10 \mathrm{~min}$. A, Phospho-JNK1/2 (A), PhosphoERK1/2 (B), Phospho-p38 (C), were determined by Western blot analysis whole cell lysates with phospho-specific Abs. ERK, p38, JNK respectively were detected from whole cell lysates. 

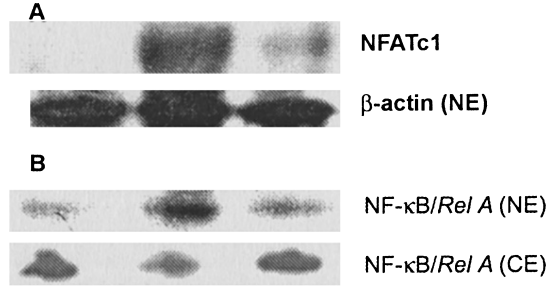

c
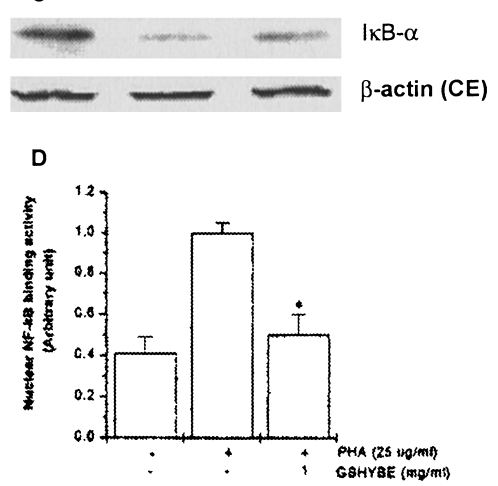

Fig. 2. Effect of GSHYBE on Nuclear Translocation of NFATc1, $\mathrm{NF} \kappa \mathrm{B} / \operatorname{Rel} A$

MOLT- 4 cells $\left(5 \times 10^{6}\right)$ were treated with GSHYBE $(1 \mathrm{mg} / \mathrm{ml})$ for $30 \mathrm{~min}$ and then stimulated with PHA $(25 \mu \mathrm{g} / \mathrm{ml})$ for $1 \mathrm{~h}$. Nuclear protein was prepared and analyzed for $\mathrm{NF}-\kappa \mathrm{B}$ by Western blotting as described in the experimental procedures. NFATc1 (A), $\mathrm{NF} \kappa \mathrm{B} / \operatorname{Rel} A(\mathrm{~B})$ in nuclear extract $(\mathrm{NE})$ and $\mathrm{I} \kappa \mathrm{B}-\alpha(\mathrm{C})$ in cytoplasmic extract $(\mathrm{CE})$. NF- $\kappa$ B binding activity was measured from nuclear lysates using a consensus NF- $\kappa$ B binding site oligonucleotide and antibody specific to the p65 subunit in an ELISA format. Result is expressed as the folds increase of the absorbance at $405 \mathrm{~nm}$ over control conditions (D). Data are presented as mean \pm S.E.M. of three independent experiments. $* p<0.05$ : significantly different from the PHA-stimulated cells.

creased binding activity was decreased by treatment of GSHYBE.

GSHYBE Inhibits IL-2 Expression Synthesis of IL-2 is an early characteristic in the activation of T cell. To investigate the effect of GSHYBE on protein expression, we stimulated PHA for $24 \mathrm{~h}$. IL-2 expression levels in intracellular of MOLT-4 cells activated by PHA, were determined by Western blot analysis. PHA-stimulated MOLT-4 cells led to an increase in IL-2 level. But pretreatment of cells with GSHYBE $(1 \mathrm{mg} / \mathrm{ml})$ decreased IL-2 protein level (Fig. 3).

GSHYBE Inhibits Production of IL-2, IL-4 and IFN- $\gamma$ To investigate the effect of GSHYBE on various cytokine secretion, MOLT- 4 cells and PBMC were stimulated for $24 \mathrm{~h}$ in the presence of GSHYBE with PHA. The quantification of IL-2, IL-4 and IFN- $\gamma$ in the supernatants was preformed using an ELISA. GSHYBE $(1 \mathrm{mg} / \mathrm{ml})$ significantly inhibited the PHA induced IL-2, IL-4 and IFN- $\gamma$ secretion from MOLT-4 cells and PBMC (Figs. 4, 5). IL-2 is a necessary cytokine for $\mathrm{T}$ cell proliferation in response to mitogen or alloantigen stimulation. GSHYBE inhibited PHA-induced proliferation from MOLT-4 cells and PBMC (Fig. 6). But, in the case of MOLT- 4 cells, the statistical difference was weak (Fig. 6A).

GSHYBE Inhibits Secretion of IL-2 on the Skin Allergic Reaction in Vivo To investigate the effect of GSHYBE on IL-2 secretion in in vivo model, we used passive cutaneous anaphylaxis (PCA). PCA is one of the most important in vivo models of local skin allergic reaction. ${ }^{18)}$ As described in the material and method, local injection of anti-DNP $\operatorname{IgE}$ followed by an intravenous antigenic challenge has been per-
A
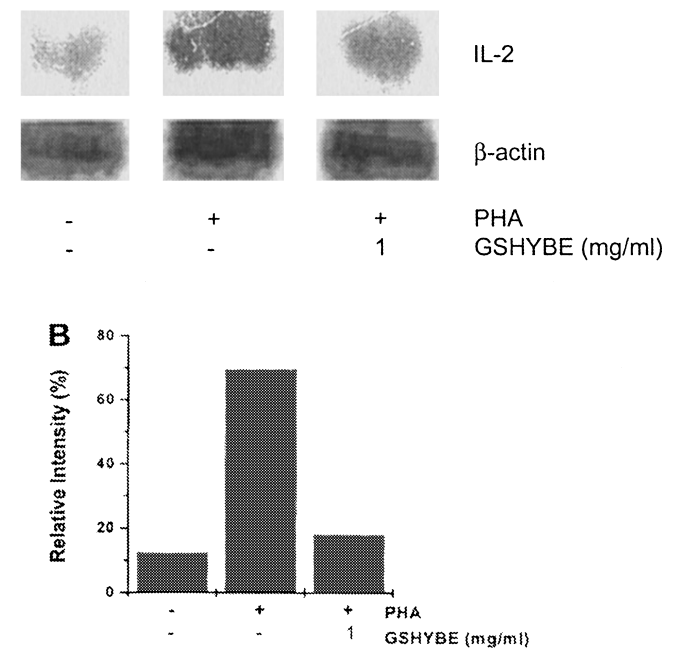

Fig. 3. Effect of GSHYBE on IL-2 Protein Expression

MOLT-4 cells were pretreated with GSHYBE $(1 \mathrm{mg} / \mathrm{ml})$ for $30 \mathrm{~min}$ then stimulated with PHA $(25 \mu \mathrm{g} / \mathrm{ml})$ for $24 \mathrm{~h}$. IL-2 protein expression was also analyzed by western blotting (A). IL-2 level was quantitated by densitometry (B).
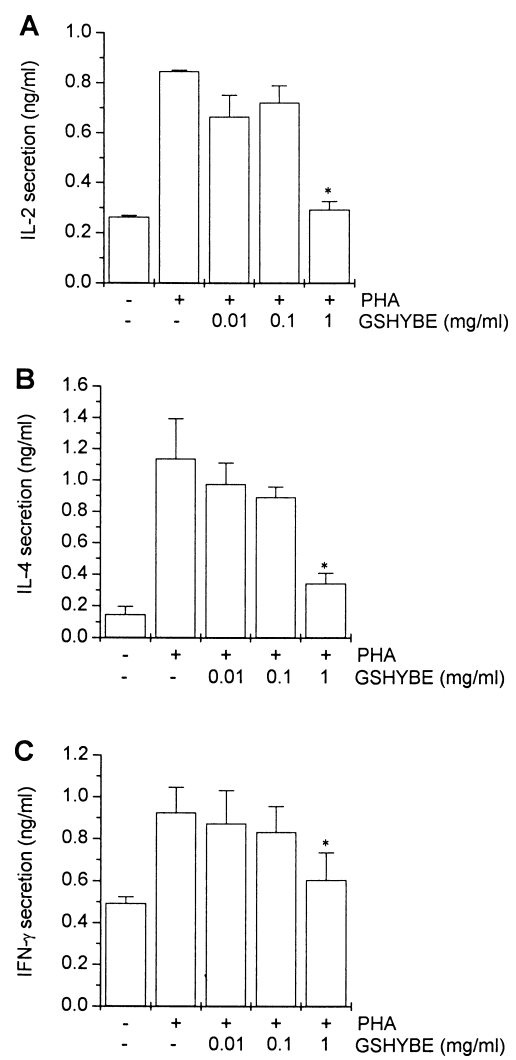

Fig. 4. Effect of GSHYBE on IL-2, IL-4 and IFN- $\gamma$ Secretion in MOLT-4 Cells

PHA-stimulated MOLT- 4 cells $\left(3 \times 10^{5}\right)$ were incubated for $24 \mathrm{~h}$ in the absence or presence of GSHYBE. IL-2, IL-4 and IFN- $\gamma$ secreted into the medium are presented as the mean \pm S.E.M. of three independent experiments. $* p<0.05$ : significantly different from PHA-stimulated value.

formed. Anti-DNP IgE was injected into dorsal skin sites. After $48 \mathrm{~h}$, all animals were injected i.v. with DNP-HSA containing Evans blue dye. The quantification of IL-2 in the supernatants of homogenaized the dosal skin was preformed using an ELISA. Oral administration of GSHYBE $(1 \mathrm{~g} / \mathrm{kg})$ 

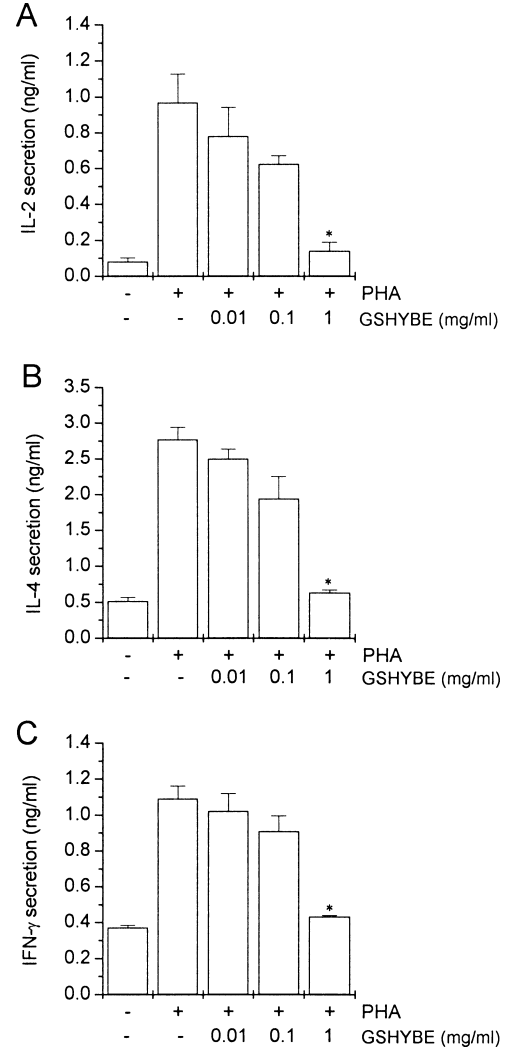

Fig. 5. Effect of GSHYBE on IL-2, IL-4 and IFN- $\gamma$ Secretion in PBMC

PHA-stimulated PBMC cells $\left(3 \times 10^{5}\right)$ were incubated for $24 \mathrm{~h}$ in the absence or presence of GSHYBE. IL-2, IL-4 and IFN- $\gamma$ secreted into the medium are presented as the mean \pm S.E.M. of three independent experiments. $* p<0.05$ : significantly different from PHA-stimulated value.
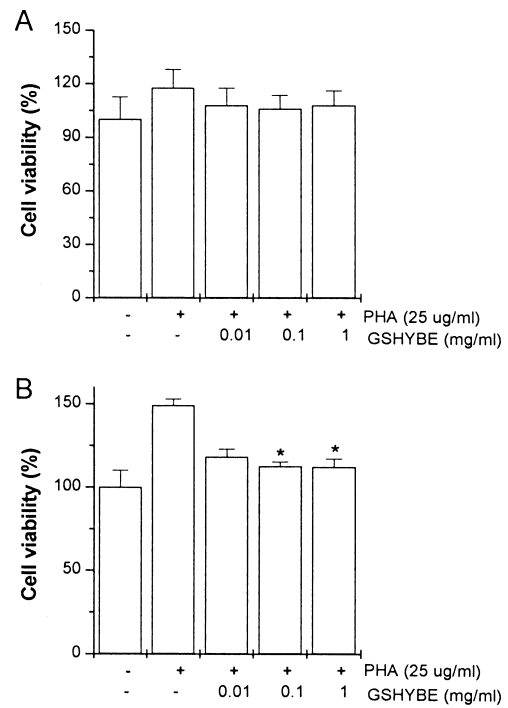

Fig. 6. Effect of GSHYBE on the Cell Viability in MOLT-4 Cells and PBMC

Cell viability was evaluated by MTT assay $24 \mathrm{~h}$ after GSHYBE treatment $(0.01-$ $1 \mathrm{mg} / \mathrm{ml}$ ) in MOLT- 4 cells (A) and PBMC (B). The percentage of viable cells was over $95 \%$ in each condition. Data represent the mean \pm S.E.M. of three independent experiments.

significantly inhibited IL-2 secretion by $52.23 \%$

\section{DISCUSSION}

In this study, we show that GSHYBE inhibit T cell activa-

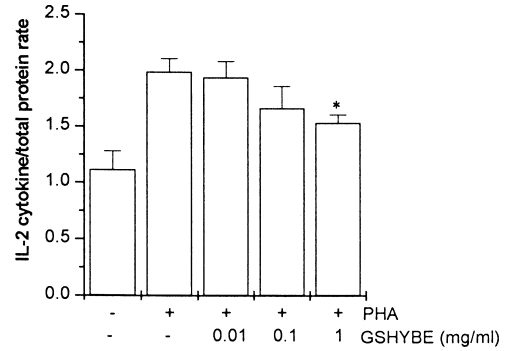

Fig. 7. Effect of GSHYBE on IL-2 Production in in Vivo Model

GSHYBE $(0.01-1 \mathrm{~g} / \mathrm{kg})$ was administered orally $1 \mathrm{~h}$ prior to the challenge with antigen in mouse (total $n=6$ ). Data represent the mean \pm S.E.M. of three independent experiments. $* p<0.05$; significantly different from the saline value.

tion by affecting distinct events of $\mathrm{T}$ cell signal transduction. GSHYBE block the nuclear localization of NFATc1 (Fig. $2 \mathrm{~A})$. Also, we showed that GSHYBE inhibited I $\kappa$ B degradation and NF- $\kappa \mathrm{B}$-dependent expression in human $\mathrm{T}$ cell line MOLT-4 cells. GSHYBE inhibited PHA-induced proliferation from MOLT-4 cells and PBMC (Fig. 6). GSHYBE $(1 \mathrm{mg} / \mathrm{ml})$ significantly inhibited IL-2 secretion from MOLT4 cells and PBMC. In addition to GSHYBE inhibits secretion of IL-2 on the skin allergic reaction in vivo. Thus, inhibition of T cell proliferation by GSHYBE can be attributed both a reduction in IL-2 production and a decreased expression.

Engagement of the TcR rapidly induces multiple signal transduction pathways. These events cause the recruitment and assembly of signal complexes that trigger different signal transduction. The pathways involved included the protein kinase C, MAPK, calcineurin. All these pathways, together with those triggered by the receptor-independent stimulants, converge on activation of promitotic transcription factors such as NFAT and NF- $\kappa$ B, which leads to proliferation and IL-2 synthesis. ${ }^{19)}$ Despite these divergent signaling pathways, GSHYBE treatment efficiently blocked IL-2 synthesis. This phenomenon suggests that GSHYBE interacts with events far upstream in the TcR signaling cascade.

In mammals, MAPK signaling cascades regulate important cellular process including gene expression, cell proliferation, cell survival and death. ${ }^{20)}$ Also, MAPK signaling cascades are activated upon stimulation of $\mathrm{T}$ cells and are involved in the regulation of numerous transcription factors including those required for IL-2 mRNA transcription. ${ }^{21,22)}$ The induction of most cytokine genes requires activation of the ERK1/2 and p38 MAPK. ${ }^{23)}$ The activity of ERK1/2 and p38 has been increased in lesional psoriatic skin compared with nonlesional psoriatic skin. ${ }^{24)}$ Thus $\mathrm{p} 38$ and ERK1/2 might be potential targets in the treatment of skin disease. Based on such clues as to the signal transduction cascade affected by activation of $T$ cell, we investigate the intracellular signaling pathways. Our results showed that ERK1/2, p38 activation were reduced by GSHYBE whereas JNK was not affected (Fig. 1).

Two of the earliest $\mathrm{T}$ cell signaling events affected was the nuclear translocation of NFAT and NF- $\kappa \mathrm{B}$. It has been proposed that nuclear accumulation of NFAT may be control by a balance between $\mathrm{Ca}^{2+} /$ calcineurin and JNK/ERK/p38 signals. ${ }^{25)}$ A common signal may be derived from the ERK MAP kinase pathway to regulate general NFAT activity. We demonstrated that nuclear translocation of NFATc1 and NF$\kappa \mathrm{B} /$ Rel $A$ is markedly reduction in activated $\mathrm{T}$ cells by 
GSHYBE (Figs. 2A, B). The suppression of nuclear NF$\kappa \mathrm{B} /$ Rel $A$ could be due to either to a failure to translocate to the nucleus even after $\mathrm{I} \kappa \mathrm{B}-\alpha$ degradation or to degradation in the nucleus. In a study of suppression of $\mathrm{T}$ cell function by renal cell carcinoma, failure to activate NF- $\kappa \mathrm{B}$ was caused in some cases by inhibition of phosphorylation and degradation of $\mathrm{I} \kappa \mathrm{B}$ and in others by a lack of NF- $\kappa \mathrm{B}$ nuclear accumulation. ${ }^{26,27)}$ Our result showed that degradation of $\mathrm{I} \kappa \mathrm{B}$ has been thought to be sufficient to cause the nuclear translocation of NF- $\kappa$ B (Fig. 2). Indeed, roles for NF- $\kappa$ B have been demonstrated in experimental models of liver, kidney, and cardiac transplantation. ${ }^{28-30)}$ Thus, NF- $\kappa \mathrm{B}$ is a potent proinflammatory signal transduction molecule in T cells.

Many studies are performed to clarify the inhibitory mechanism of $\mathrm{T}$ cell activity. Azodicarbonamide is known as a new $T$ cell immunosuppressant that acts in the early phase of $\mathrm{T}$ cell activation by inhibiting intracellular mobilization of calcium. ${ }^{31)}$ Pyrazole compounds are a potent inhibitor of NFAT activation and T cell cytokine production. ${ }^{32}{ }^{32}$ We tried to chase the main acting compound from GSHYBE. Hence we fractionated GSHYBE and HPLC assay (data not shown). We identified 15 separate compounds however we could not defined each compound at this time. More detailed study on defining actual compound is needed.

In summary, we showed that GSHYBE attenuated PHA induced ERK and p38 MAPK, degradation of $\mathrm{I} \kappa \mathrm{B}-\alpha$ and NF$\kappa \mathrm{B}$-dependent activation. GSHYBE and CsA produced very similar inhibition effects on NFATc1, NF- $\kappa$ B activation and IL-2 protein expression (data not shown). Further, IL-2 secretion was significantly inhibited in MOLT-4 cells and PBMC by $94.8,92.3 \%$, respectively (Fig. 4). By providing detailed insight into the influence of GSHYBE on human T cell activation, these data considerably enhance our understanding of how these substances exert their immunomodulatory effects.

Acknowledgements This study was supported by part of a grant from Biogreen 21 Research Center funded by Rural Development Administration of the Korean government.

\section{REFERENCES}

1) Lee U. H., Hong S. Y., "Principle of Constitutional Medicine," Heingrin Press, Seoul, 1992, p. 300.

2) Chung S. H., Terashi H., Rhodes L. M., Moon N., Dunham W. R., Marcelo C. L., J. Ethnopharmacol., 74, 53-61 (2001).

3) Hwang D. Y., "Bangyakhappyun," Nam-san-dang Press, Seoul, 1992, p.164

4) Chan A. C., Desai D. M., Weiss A., Annu. Rev. Immunol., 12, 555-
592 (1994)

5) Garrington T. P., Johnson G. L., Curr. Opin. Cell Biol., 11, 211-218 (1999).

6) Masuda E. S., Imamura R., Amasaki Y., Arai K., Arai N., Cell. Signal., 10, 599-611 (1998).

7) Karin M., Oncogene, 18, 6867-6874 (1999).

8) Baeuerle P. A., Henkel T., Annu. Rev. Immunol., 12, 141-179 (1994).

9) Rao A., Luo C., Hogan P. G., Annu. Rev. Immunol., 15, 707-747 (1997).

10) Lyakh L., Ghosh P., Rice N. R., Mol. Cell. Biol., 17, 2475-2484 (1997).

11) Northrop J. P., Ho S. N., Chen L., Thomas D. J., Timmerman L. A., Nolan G. P., Admon A., Crabtree G. R., Nature (London), 369, 497502 (1994).

12) Mercurio F., Manning A. M., Curr. Opin. Cell Biol., 11, 226-232 (1999).

13) May M. J., Ghosh S., Semin. Cancer Biol., 8, 63-73 (1997).

14) Cantrell D., Annu. Rev. Immunol., 14, 259-274 (1996).

15) Schoonbroodt S., Legrand-Poels S., Best-Belpomme. M., Piette J., Biochem. J., 321, 777-785 (1997).

16) Scuderi P., Sterling K. E., Lam K. S., Finley P. R., Ryan K. J., Ray C. G., Petersen E., Slymen D. J., Salmon S. E., Lancet, 2, 1364-1365 (1986).

17) Romagnoli P., Bron C., J. Immunol., 158, 5757-5764 (1997).

18) Wershil B. K., Mekori Y. A., Galli S. J., J. Immunol., 139, 2605-2614 (1987).

19) Werlen G., Palmer E., Cur. Opin. Immunol., 14, 299-305 (2002).

20) Kishore R., McMullen M. R., Nagy L. E., J. Biol. Chem., 276, $41930-41937$ (2001).

21) Hardy K., Chaudhri G., Immunol. Cell Biol., 75, 528—545 (1997).

22) Rincon M., Conze D., Weiss L., Diehl N. L., Fortner K. A., Yang D., Flavell R. A., Enslen H., Whitmarsh A., Davis R. J., Immunol. Cell Biol., 78, 166-175 (2000).

23) Shapiro L., Dinarello C. A., Proc. Natl. Acad. Sci. U.S.A., 92, 12230 12234 (1995).

24) Johansen C., Kragballe K., Westergaard M., Henningsen J., Kristiansen K., Iversen L., Br. J. Dermatol., 152, 37-42 (2005).

25) Porter C. M., Havens M. A., Clipstone N. A., J. Biol. Chem., 275, $3543-3551(2000)$

26) Ling W., Rayman P., Uzzo R., Clark P., Kim H. J., Tubbs R., Novick A., Bukowski R., Hamilton T., Finke J., Blood, 92, 1334-1341 (1998).

27) Kolenko V., Bloom T., Rayman P., Bukowski R., His E., Finke J., J. Immunol., 163, 590-598 (1999).

28) Zwacka R. M., Zhang Y., Zhou W., Halldorson J., Engelhardt J. F., Hepatology, 28, 1022-1030 (1998).

29) Bradham C. A., Schemmer P., Stachlewitz R. F., Thurman R. G., Brenner D. A., Liver Transplantation Sur, 5, 282-293 (1999).

30) Cooper M., Lindholm P., Pieper G., Seibel R., Moore G., Nakanishi A., Dembny K., Komorowski R., Johnson C., Adams M., Roza A., Transplantation, 66, 838-844 (1998).

31) Tassignon J., Ismaili J., Le Moine A., Van Laethem F., Leo O., Vandevelde M., Goldman M., Nature Med., 5, 947-950 (1999).

32) Trevillyan J. M., Chiou X. G., Chen Y. W., Ballaron S. J., Sheets M. P., Smith M. L., Wiedeman P. E., Warrior U., Wilkins J., Gubbins E. J., Gagne G. D., Fagerland J., Carter G. W., Luly J. R., Mollison K. W., Djuric S. W., J. Biol. Chem., 276, 48118-48126 (2001). 